\title{
Estimating the burden of adult hospital admissions due to RSV and other respiratory pathogens in England
}

\author{
Ashley Sharp ${ }^{1}$, Mehdi Minaji ${ }^{2}$, Nikolaos Panagiotopoulos ${ }^{2}$, Rachel Reeves ${ }^{2}$, Andre \\ Charlett $^{2}$, and Richard Pebody ${ }^{3}$ \\ ${ }^{1}$ Public Health England Colindale \\ ${ }^{2}$ Public Health England \\ ${ }^{3}$ World Health Organization Regional Office for Europe
}

August 5, 2021

\begin{abstract}
Respiratory Syncytial Virus (RSV) is a common seasonal respiratory virus and an important cause of illness among infants, but the burden of RSV disease is not well described among the older population. The objective of this study was to estimate the age-specific incidence of hospital admission among over 65 s due to respiratory illnesses attributable to RSV in England to inform optimal vaccine and therapeutic interventions. We used linear multiple regression to examine the effect of changes in weekly counts of respiratory pathogens on the weekly counts of respiratory hospital admissions. The study population was all patients aged 65 years or over admitted to English hospitals between 2nd August 2010 and 30th July 2017. RSV was estimated to account for a seasonal annual average of 71 (95\% CI 52-90) respiratory admissions per 100,000 in adults age 65-74 and 251 (95\% CI 186-316) admissions per 100,000 adults age 75+. Pneumococcus was the pathogen responsible for highest annual average respiratory admission with 448 (95\% CI 310-587) admissions per 100,000 adults age 65-74 and 1010 (95\% CI 527-1493) admissions per 100,000 adults aged $75+$. This study shows that RSV continues to exert a significant burden of disease among older adults in England. These findings will support development of policy for the use of RSV therapeutics and vaccines in this age group.
\end{abstract}

\section{Hosted file}

RSV 65+ time series paper V1.0.docx available at https://authorea.com/users/429275/ articles/532998-estimating-the-burden-of-adult-hospital-admissions-due-to-rsv-and-otherrespiratory-pathogens-in-england 